\title{
Transient expression of keratin during neuronal development in the adult rabbit spinal ganglion
}

\author{
Hirohiko Iwatsuki · Masumi Suda
}

Received: 6 November 2008/ Accepted: 19 June 2009/Published online: 22 July 2009

(C) Japanese Association of Anatomists 2009

\begin{abstract}
A few neurons of the adult rabbit spinal ganglion express keratin. To examine the characters of these keratin-positive neurons, six kinds of intermediate filament proteins, namely keratin 8 , keratin 14 , nestin, vimentin, neurofilament 68 (NF-L) and glial fibrillary acidic protein (GFAP), were investigated immunohistochemically in developing and adult rabbit spinal ganglia. At 15 days of gestation, the spinal ganglion increased rapidly in volume and mainly consisted of three kinds of cells: small cells expressing vimentin, spindle-shaped cells co-expressing vimentin and nestin, and ovoid cells with an eccentric nucleus expressing nestin. Since some ovoid cells coexpressed nestin with either NF-L or GFAP, the ovoid cell may be considered to be an embryonic neural stem cell of the ganglion. In addition, a few keratin-positive polymorphic cells could be observed among these three kinds of cells. These polymorphic cells expressed five kinds of intermediate filament proteins, namely keratin 8 , keratin 14, nestin, NF-L and GFAP. These cells were also detected in newborn and adult ganglia. A few neurons in the adult ganglion also expressed these five kinds of proteins as a Golgi-associated network. However, neurons expressing these proteins could not be detected in embryonic and newborn ganglia. Therefore, it may be considered that the keratin-positive polymorphic cell is a postnatal neural stem cell of the ganglion and that neurons transiently express keratin when polymorphic cells differentiate into neurons.
\end{abstract}

Keywords Keratin $\cdot$ Nestin $\cdot$ Neuron $\cdot$ Spinal ganglion · Stem cell

H. Iwatsuki $(\bowtie) \cdot$ M. Suda

Department of Anatomy, Kawasaki Medical School,

Matsushima 577, Kurashiki 701-0192, Japan

e-mail: iwatsuki@med.kawasaki-m.ac.jp

\section{Introduction}

It has already been established that neural stem cells reside in the central nervous system of adult mammals (Zhao et al. 2003; Xu et al. 2005; Charrier et al. 2006; Hsu et al. 2007). Recently, neural stem cells have also been isolated from the peripheral nervous system, such as the spinal ganglion ( $\mathrm{Li}$ et al. 2007), enteric nervous system (Bondurand et al. 2003) and cochlea spiral ganglion (Rask-Andersen et al. 2005). However, there has been controversy regarding which type of cells serves as the source of postnatal stem cells in vivo.

Presently, at least 65 members of the intermediate filament protein family have been identified (Herrmann et al. 2003; Oshima 2007), and their expression is sensitively reflected in the cell differentiation occurring in histogenesis and disease (Albers and Fuchs 1992; Iwatsuki 1999; Herrmann et al. 2007; Iwatsuki and Suda 2007). Therefore, they have been utilized as valuable histochemical markers of cell differentiation (Iwatsuki et al. 1999, 2002). Primary neurulation involves formation of the neural plate, and the intermediate filaments expressed in the neuroepithelial cells of this plate are mainly nestin filaments (Lendahl et al. 1990). During formation of the neural groove, the nestin in neuroepithelial cells decreases concomitantly with an increase in vimentin, and these cells of the neural tube predominantly express vimentin (Kumano et al. 2001). Remarkable vimentin-neurofilament (NF) and vimentinglial fibrillary acidic protein (GFAP) transitions occur at the time of neural and glial differentiation, respectively (Bignami et al. 1982; Bignami and Dahl 1985). Although keratin is broadly expressed in epithelial cells (Albers and Fuchs 1992), it has also been detected recently in normal nervous tissue, such as the bovine neural plate (MaddoxHyttel et al. 2003), mouse neural crest cells (Katagata et al. 
1999), radial glia of the human spinal cord (Walder et al. 2003), rat ependymal cells (Kasper 1992), neurons of the human cochlea spiral ganglion (Anniko et al. 1990; Okabe et al. 1997) and neurons of the adult rabbit spinal ganglion (Iwatsuki and Suda 2005b). In addition, keratin has also been detected in the cells of the following tumors of the nervous system: paragangliomas (Moran et al. 1997; Chetty et al. 1998), spinal ependymomas (Takeuchi et al. 2002), schwannomas (Guarino 1993), choroid plexus papillomas (Yamada et al. 1998), astrocytomas (Yamada et al. 1998) and oligodendrogliomas (Kashima et al. 1993). Since keratin has been detected not only in undifferentiated neuronal cells but also in dedifferentiated tumor cells of the nervous system, it seems that keratin, in addition to nestin, could also be utilized as a valuable histochemical marker for nervous system stem cells.

We hypothesize that neural stem cells in the adult rabbit spinal ganglion contain keratin and nestin, since both proteins have been detected in a few neurons of the ganglion (Iwatsuki and Suda 2005b). To confirm our hypothesis, expression patterns of six kinds of intermediate filament proteins, namely keratin 8, keratin 14, nestin, vimentin, neurofilament 68 (NF-L) and GFAP, were analyzed immunohistochemically in developing and adult rabbit spinal ganglia.

\section{Materials and methods}

In rabbit embryos, a group of neural crest cells appears at the dorsolateral aspect of the neural tube at 10-11 days of gestation, and they begin to differentiate into the neurons at 14-15 days of gestation (Tennyson 1965). Therefore, spinal ganglia were prepared from rabbit fetuses at 15, 20 and 25 days of gestation, from newborn and adult (15 weeks of age) rabbits (Japan white rabbit; Japan Lamb Ltd., Hiroshima, Japan). Pregnant rabbits were deeply anesthetized with an intravenous injection of sodium pentobarbital, and fetuses were immediately removed. Newborn and adult rabbits were also deeply anesthetized with sodium pentobarbital. Their cervical spinal ganglia were fixed in $4 \%$ paraformaldehyde in $100 \mathrm{mM}$ phosphate buffer $(\mathrm{pH} 7.4)$ for $4 \mathrm{~h}$ at $4{ }^{\circ} \mathrm{C}$, and were successively washed in chilled phosphate-buffered saline (PBS) for $16 \mathrm{~h}$, after which they were dehydrated and embedded in paraffin.

\section{Double immunofluorescence staining}

Double immunofluorescence staining was performed to investigate dual expression among six kinds of intermediate filament proteins, namely: keratin 8 , keratin 14 , nestin, vimentin, NF-L and GFAP. Deparaffinized sections were immersed in $1 \%$ bovine serum albumin (BSA) in PBS for $30 \mathrm{~min}$. Then the sections were exposed to one of the monoclonal antibodies shown in Table 1 for $1 \mathrm{~h}$ and washed in PBS. The antibody was diluted with PBS containing $0.1 \%$ BSA. Next, they were incubated in a solution containing biotinylated horse anti-mouse IgG antibody for $30 \mathrm{~min}$ and rinsed in PBS. Then they were incubated in Alexa Fluor 488-conjugated Streptavidin (Molecular Probes, Carlsbad, CA) for $30 \mathrm{~min}$. After washing, they were exposed to another monoclonal antibody coupled to Alexa Fluor 555, which was prepared using the Alexa Fluor labeling kit (Molecular Probes). When using anticytokeratin 8 and anti-vimentin antibodies, the sections were pretreated in 10U/ml trypsin (EC 3.4.21.4, type 1, Sigma) in PBS before the first immunoreaction. After immunostaining, they were finally coverslipped with a mounting medium containing 4',6'-diamino-2-phenylindole to counterstain DNA (Vectashield; Vector Laboratories, Burlingame, CA). Negative controls were exposed to PBS containing $0.1 \%$ BSA or preimmune horse serum instead of the antibodies. No immunostaining was observed in the negative control sections.

Table 1 Mouse monoclonal antibodies used in this study

\begin{tabular}{lllll}
\hline Antibody & Clone & Supplier & Dilution & Reference \\
\hline Anti-cytokeratin 8 antibody & M20 & Sigma $^{\mathrm{a}}$ & $1: 200$ & Van Muijen et al. (1987) \\
Anti-cytokeratin 14 antibody & CKB1 & Sigma & $1: 200$ & Caselitz et al. (1986) \\
Anti-GFAP antibody & G-A-5 & Sigma & $1: 400$ & Franke et al. (1991) \\
Anti-nestin antibody & MAB5326 & Chemicon & Messam et al. (2000) \\
Anti-neurofilament 68 & NR4 & Sigma & $1: 200$ & Franke et al. (1991) \\
Anti-vimentin & Vim3B4 & Dako $^{\text {c }}$ & $1: 400$ & Azumi and Battifora (1987)
\end{tabular}

\footnotetext{
${ }^{a}$ Sigma, St. Louis, MO

b Chemicon International, Temecula, CA

c Dako Japan, Kyoto, Japan
} 
Immunoelectron microscopical staining

K8 and NF-L were essentially visualized using a preembedding avidin-biotin complex (ABC) method (Vectastain Elite ABC kit; Vector Laboratories, Burlingame, CA) except for minor modifications. The adult cervical spinal ganglia were fixed in $4 \%$ paraformaldehyde containing $0.1 \%$ glutaraldehyde and $100 \mathrm{mM}$ cacodylate buffer $(\mathrm{pH}$ 7.4) for $2 \mathrm{~h}$ at $4^{\circ} \mathrm{C}$ and washed in chilled PBS for $16 \mathrm{~h}$. Then they were sliced into leaf-like pieces, $40 \mu \mathrm{m}$ in thickness, using a microslicer (DTK-3000, Dosaka EM, Kyoto, Japan). The sliced tissue samples were incubated in PBS containing $0.3 \%$ triton X-100 and $1 \%$ BSA for 2 days at $4{ }^{\circ} \mathrm{C}$, and then immersed in $0.3 \%$ hydrogen peroxide in methanol for $30 \mathrm{~min}$. After incubation in normal horse serum in PBS for $4 \mathrm{~h}$, the tissues were exposed to either anti-cytokeratin 8 or anti-NF-L antibody solution containing $0.1 \%$ BSA and $0.1 \%$ triton $\mathrm{X}-100$ for 3 days at $4{ }^{\circ} \mathrm{C}$ and successively washed in PBS. Then they were immersed in biotinylated horse anti-mouse $\operatorname{IgG}$ antibody for $16 \mathrm{~h}$ at $10^{\circ} \mathrm{C}$, washed in PBS and reacted with $\mathrm{ABC}$ reagent for $2 \mathrm{~h}$ at room temperature. After washing in PBS, they were incubated in a peroxidase substrate solution containing $0.02 \% 3,3^{\prime}$-diaminobenzidine, $0.005 \%$ hydrogen peroxide and $50 \mathrm{mM}$ Tris- $\mathrm{HCl}$ buffer ( $\mathrm{pH}$ 7.6) for $20 \mathrm{~min}$ and washed in PBS. Then they were postfixed in $2 \%$ osmium tetroxide in $100 \mathrm{mM}$ cacodylate buffer $(\mathrm{pH} \mathrm{7.4)}$ for $60 \mathrm{~min}$ at $4^{\circ} \mathrm{C}$ and for $30 \mathrm{~min}$ at room temperature, dehydrated and embedded in Epon 812. The ultrathin sections were stained with uranyl acetate and observed with a Hitachi H-7100 electron microscope. Negative controls were exposed to PBS containing $0.1 \%$ BSA or preimmune horse serum instead of the primary antibody. No reaction was recognized in the negative control tissues.

For the study of normal ultrastructure, some tissues were fixed in $2.5 \%$ glutaraldehyde in $70 \mathrm{mM}$ cacodylate buffer (pH 7.4) for $2 \mathrm{~h}$ at room temperature and postfixed with $1 \%$ osmium tetroxide in $150 \mathrm{mM}$ cacodylate buffer ( $\mathrm{pH}$ 7.4) for $90 \mathrm{~min}$ at $4^{\circ} \mathrm{C}$. After dehydration, they were embedded in Epon 812. Ultrathin sections were stained with uranyl acetate and lead citrate.

This study was approved by the Animal Research Committee of Kawasaki Medical School (no. 08-052) and conducted according to the "Guide for the Care and Use of Laboratory Animals" of Kawasaki Medical School.

\section{Results}

Fifteen days of gestation

At 15 days of gestation, the rudiments of the spinal ganglia increased rapidly in volume and were mainly composed of three kinds of ganglion cells, namely, small cells with scant cytoplasm, spindle-shaped cells and ovoid cells with an eccentric nucleus (Fig. 1a, Table 2). To characterize these cells, double immunofluorescence of vimentin with nestin was performed (Fig. 1b). The small cells expressed vimentin alone, the spindle-shaped cells co-expressed vimentin and nestin, and the ovoid cells with an eccentric nucleus expressed nestin alone. To further clarify the nature of the ovoid cells, double staining of nestin with NF-L was performed (Fig. 1c). Three kinds of ovoid cells were recognized, namely, cells expressing nestin alone, cells expressing NF-L alone and cells co-expressing both proteins. The ovoid cells expressing nestin alone were smaller than the NF-L-positive ovoid cells (Table 2). When double-staining of nestin with GFAP was performed, a few ovoid cells co-expressed nestin and GFAP, but ovoid cells expressing GFAP alone were very few (Fig. 1d). To detect other kinds of cells in the ganglion, double stainings of keratin with other intermediate filament proteins were also performed. A few small polymorphic cells expressed keratin (Tables 2, 3). In these keratin-positive cells, coexpressions of keratin 8 and keratin 14 (Fig. 1e), keratin 8 and nestin (Fig. 1f), keratin 8 and NF-L (Fig. 1g), and keratin 14 and GFAP (Fig. 1h) were recognized. In these cells, however, tight co-localization between keratin 8 and keratin 14 in the cytoplasm could not be observed. In addition, a few small polymorphic cells co-expressed NF-L and GFAP (Fig. 1i), but cells co-expressing keratin and vimentin could not be detected.

Twenty days of gestation

At 20 days of gestation, a decrease in the number of vimentin-positive small cells and an increase in the number of nestin-positive ovoid cells with an eccentric nucleus occurred (Table 3). Similar to the spinal ganglion at 15 days of gestation, a few small polymorphic cells expressing keratin were also observed (Table 3 ). In these cells, co-expressions of keratin 8 and keratin 14, keratin 8 and nestin, keratin 8 and NF-L, and keratin 14 and GFAP were recognized, and a few small polymorphic cells coexpressing NF-L and GFAP were also observed (data not shown).

Twenty-five days of gestation and newborn

At 25 days of gestation, many pseudounipolar neurons were observed, and differentiated satellite cells began to surround them (Fig. 2a). The formation of the ganglion was completed after birth, and its structure was similar to that of the adult ganglion. In the ganglion at 25 days of gestation, there were no vimentin-positive small cells, and the number of nestin-positive ovoid cells with an eccentric 

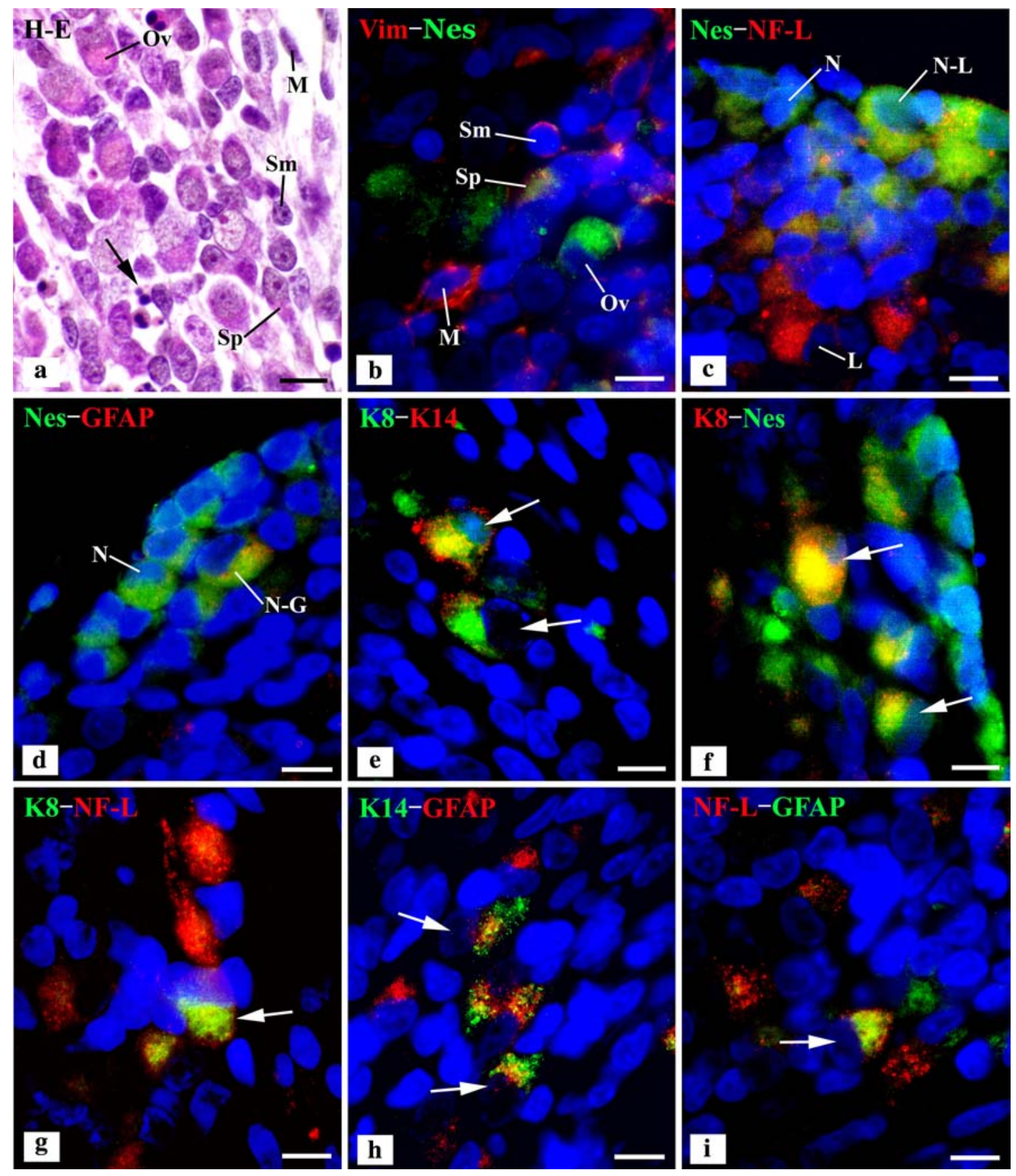

Fig. 1 Spinal ganglia at 15 days of gestation. Bar $10 \mu \mathrm{m}$. a H\&E staining. Three kinds of cells, namely small cells $(\mathrm{Sm})$, spindle-shaped cells $(S p)$ and ovoid cells $(O v)$, are distinguishable at this stage. The nucleus of the small cells is slightly larger and paler than that of mesenchymal cells $(M)$. Some apoptotic cells (arrow) are recognized. Double immunofluorescence staining of two kinds of intermediate filament proteins. b Vimentin (Vim; red) and nestin (Nes; green). Small cells $(\mathrm{Sm})$ express vimentin and ovoid cells $(\mathrm{Ov})$ express nestin alone, but spindle-shaped cells $(S p)$ co-express both proteins. Mesenchymal cells $(M)$ also express vimentin. c Nestin (green) and

nucleus was reduced dramatically (Table 3). A few nestinpositive ovoid cells existed in the peripheral zone of the ganglion. Differentiated neurons expressed NF-L, and
NF-L (red). Smallish ovoid cells express nestin alone $(N)$, but largish ovoid cells express NF-L alone $(L)$ or both proteins $(N-L)$. d Nestin (green) and GFAP (red). Both proteins are co-expressed in a few largish ovoid cells $(N-G)$. Smallish ovoid cells $(N)$ express nestin alone. A few polymorphic cells (arrows) co-express keratin $8(K 8)$, keratin 14 (K14), nestin, NF-L and GFAP: e keratin 8 (green) and keratin 14 (red), f keratin 8 (red) and nestin (green), g keratin 8 (green) and NF-L (red), h keratin 14 (green) and GFAP (red), and i NF-L (red) and GFAP (green)

satellite cells co-expressed GFAP and vimentin (data not shown). The nestin-positive ovoid cells could not be observed in the newborn ganglion. As shown in Fig. 2b-e, 
Table 2 Size of cells observed in the spinal ganglion at 15 days of gestation

Table 3 Incidence of nestinpositive ovoid cells and keratinpositive polymorphic cells in spinal ganglial cells
Cells

Size (diameter $\times$ length), $\mu \mathrm{m}$

Small cell expressing vimentin alone

$4.5-6 \times 6.5-8.0$

Spindle-shaped cell co-expressing vimentin and nestin

$6.5-7.5 \times 14-16.5$

Ovoid cell expressing nestin alone

$10-12 \times 11.5-12.5$

Ovoid cell expressing NF-L

$15-17 \times 17-20$

Polymorphic cell expressing keratin

\begin{tabular}{lll}
\hline Stage & Nestin-positive ovoid cells $(\%)$ & $\begin{array}{l}\text { Keratin 8/14 positive } \\
\text { polymorphic cells }(\%)\end{array}$ \\
\hline E15d & $44.4 \pm 3.3(n=3)$ & $3.2 \pm 0.8(n=4)$ \\
E20d & $62.0 \pm 3.9(n=3)$ & $2.9 \pm 1.0(n=5)$ \\
E25d & $14.1 \pm 4.4(n=3)$ & $1.4 \pm 0.7(n=5)$ \\
Newborn & $0(n=2)$ & $1.3 \pm 0.7(n=5)$ \\
Adult & $0(n=2)$ & $0.2 \pm 0.1(n=5)$
\end{tabular}
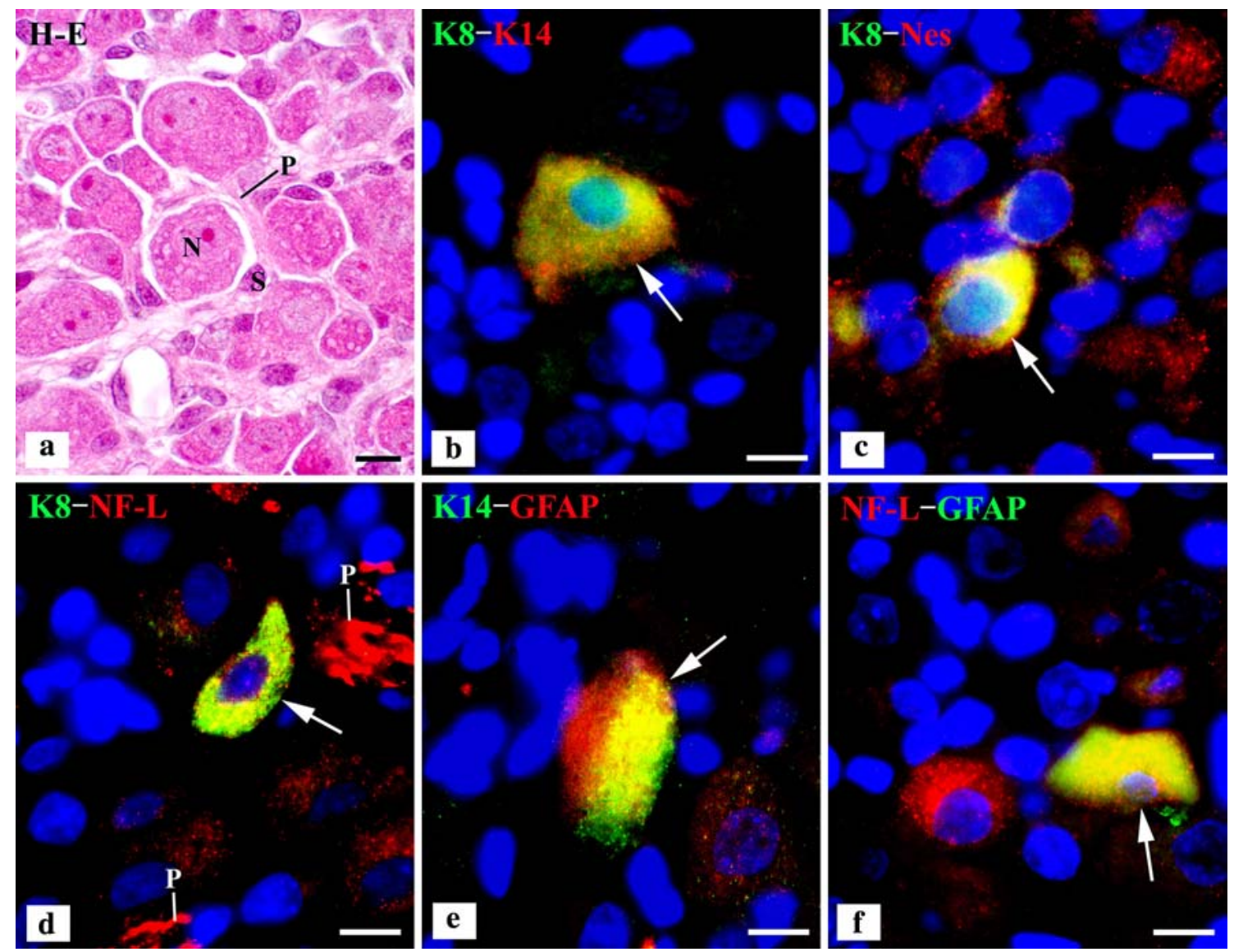

Fig. 2 Spinal ganglia at 25 days of gestation (a, c, d, f) and in newborn (b, e). Bar $10 \mu \mathrm{m}$. a H\&E staining. Satellite cells $(S)$ begin to surround a neuron $(N)$. The nucleus of the neuron is large, pale and centrally placed within the perikaryon. $P$ the process of the neuron. Double immunofluorescence staining of two kinds of intermediate filament proteins. A few polymorphic cells (arrows) co-express keratin 8, keratin 14, nestin, NF-L and GFAP: b Keratin 8 (green) and keratin 14 (red), c keratin 8 (green) and nestin (red), d keratin 8 (green) and NF-L (red), e keratin 14 (green) and GFAP (red), and $\mathbf{f}$ NF-L (red) and GFAP (green). Strong staining for NF-L is also seen in the processes $(P)$ of neurons 

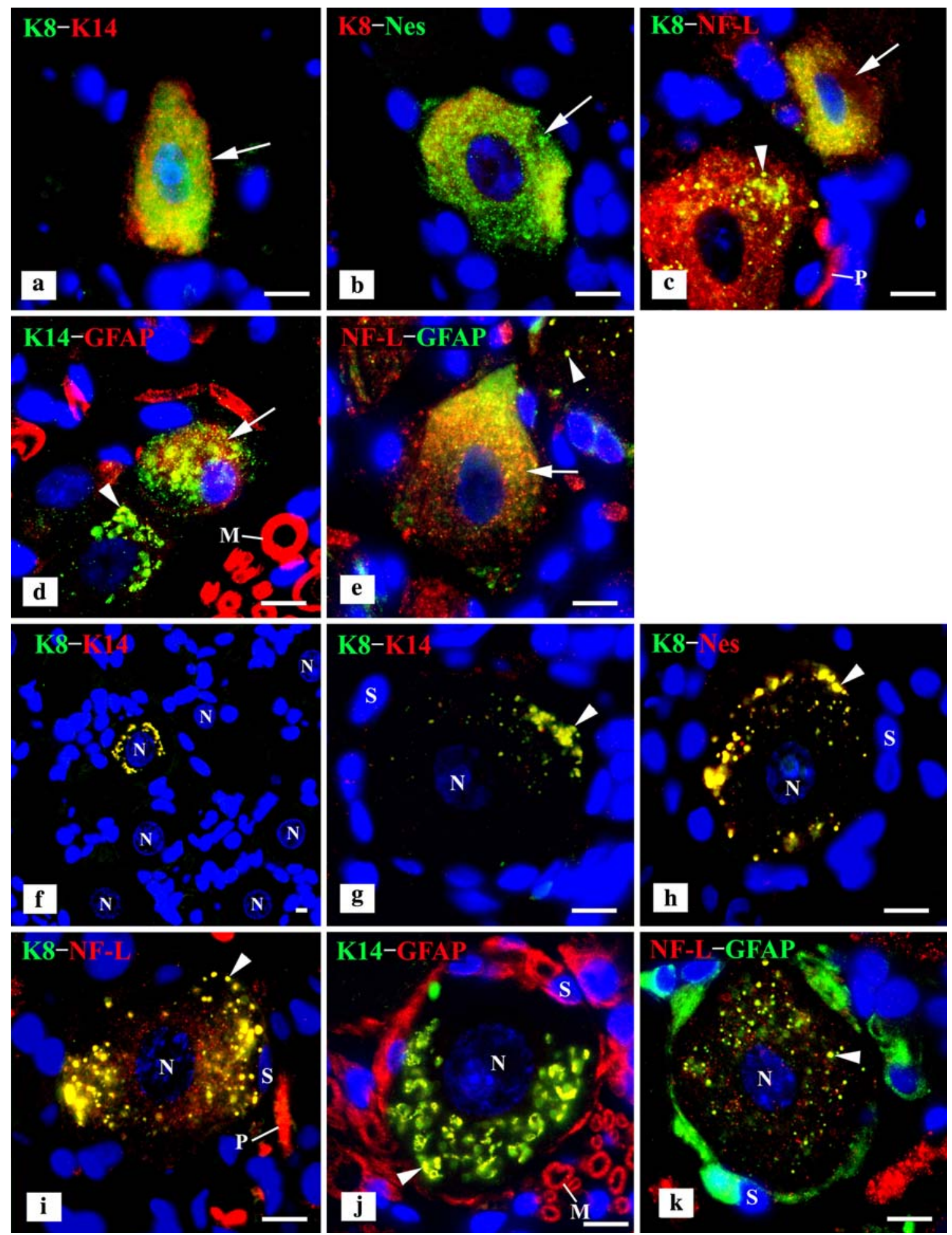

Fig. 3 Double immunofluorescence staining of two kinds of intermediate filament proteins in the adult spinal ganglia. Bar $10 \mu \mathrm{m}$. A few polymorphic cells (arrows) co-express keratin 8, keratin 14, nestin, NFL and GFAP: a keratin 8 (green) and keratin 14 (red), b keratin 8 (red) and nestin (green), c keratin 8 (green) and NF-L (red), d keratin 14 (green) and GFAP (red), and e NF-L (red) and GFAP (green). In addition, the neighboring neurons also co-express these proteins as peculiar granules (arrowheads). $P$ NF-L-positive process of neuron. $M$,
GFAP-positive myelin sheath.f Low magnification of keratin 8 (green) and keratin 14 (red) double staining. Both keratins are co-expressed in a few neurons. $N$ neuron. A few neurons $(N)$ co-expressing keratin 8 , keratin 14, nestin, NF-L and GFAP as peculiar granular or network structures (arrowheads) in their perikarya are surrounded by satellite cells (S): g Keratin 8 (green) and keratin 14 (red), h keratin 8 (green) and nestin (red), i keratin 8 (green) and NF-L (red), j keratin 14 (green) and GFAP (red), and $\mathbf{k}$ NF-L (red) and GFAP (green) 
a few polymorphic cells expressing keratin were also observed at these stages (Table 3). In these cells, coexpressions of keratin 8 and keratin 14, keratin 8 and nestin, keratin 8 and NF-L, and keratin 14 and GFAP were recognized, and a few polymorphic cells co-expressing NFL and GFAP were also observed (Fig. 2f). However, keratin-positive neurons could not be detected at these stages.

\section{Adult}

In the adult ganglion, the expression of NF-L in the neurons decreased, whereas that of GFAP in the satellite cells increased. As shown in Table 3, very few keratin-positive polymorphic cells also existed in the adult ganglion. In these cells, co-expressions of keratin 8 and keratin 14, keratin 8 and nestin, keratin 8 and NF-L, and keratin 14 and

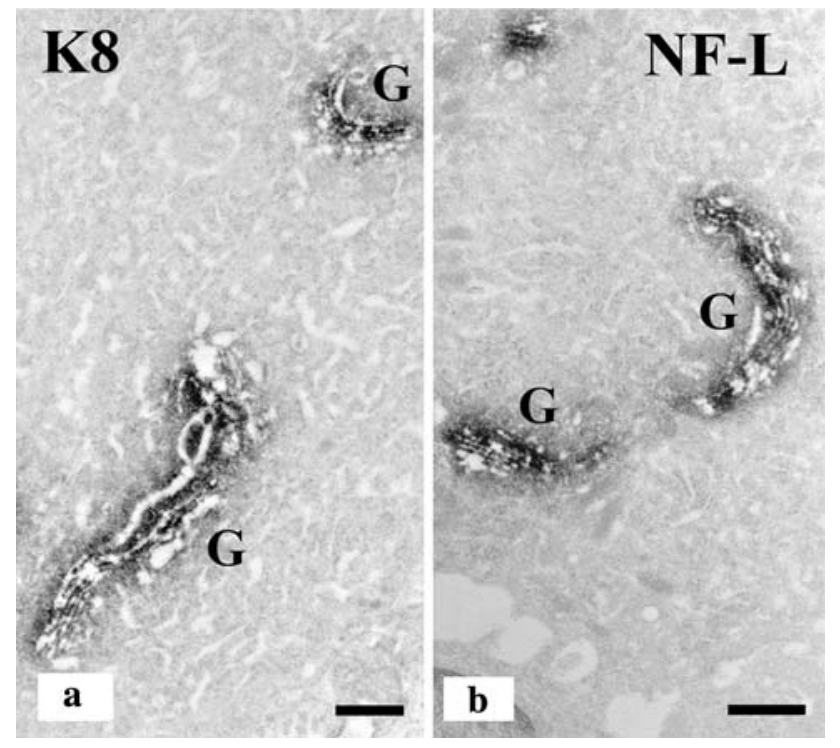

Fig. 4 Immunoelectron microscopic staining of keratin 8 (a) and NF$\mathrm{L}$ (b) in the neurons of the adult spinal ganglia. Both proteins are localized around the Golgi apparatus $(G)$, especially in association with the Golgi cisternae in a few neurons. Bar $1 \mu \mathrm{m}$
GFAP were recognized (Fig. 3a-d). In these cells, however, tight co-localization between keratin 8 and keratin 14 in the cytoplasm could not be observed (Fig. 3a). A few polymorphic cells co-expressing NF-L and GFAP were also recognized (Fig. 3e). In addition, a few neurons surrounded by satellite cells, about $7 \%$ of neurons, also expressed keratin (Fig. 3f). In these neurons, keratin 8, keratin 14, nestin, NF-L and GFAP came together and formed some peculiar granular or network structures in their perikarya (Fig. 3g-k). In these peculiar structures, keratin 8 and keratin 14 were tightly co-localized (Fig. 3f, g). These keratin-positive peculiar structures could not be observed in the embryonic and newborn neurons of the spinal ganglion. To clarify the natures of these peculiar structures, keratin 8 and NF-L were examined immunoelectron microscopically. Keratin 8 was distributed around Golgi cisternae, vesicles and vacuoles, and especially in association with flattened lamellar paralleled membranes in a few neurons (Fig. 4a). NF-L also surrounded the Golgi apparatus in a few neurons, and the distribution patterns were quite similar to those of keratin 8 (Fig. 4b). As shown in Fig. 5, these distribution patterns could be confirmed ultrastructurally. Many Golgi apparatuses were observed in the perikaryon of the neurons, and these Golgi apparatuses were surrounded by dense bundles of intermediate filaments. Changes in the intermediate filament composition of the ganglion cells in the developing and adult rabbit spinal ganglia are schematically summarized in Fig. 6.

\section{Discussion}

The analysis of intermediate filament protein has generated useful information about cell lineage and cell differentiation (for references see "Introduction"). In this study, two kinds of cell lineages in the neurogenesis were recognized in the developing and adult rabbit spinal ganglia by analysis of intermediate filament protein expressed in the
Fig. 5 Ultrastructure of a neuron of the adult spinal ganglion. a Many Golgi apparatuses $(G)$, which are represented in yellow, exist in a neuron. $N c$ nucleus of the neuron. Bar $1 \mu \mathrm{m}$. b Dense bundles of intermediate filaments (arrows) are observed around two Golgi apparatuses. Bar $0.3 \mu \mathrm{m}$
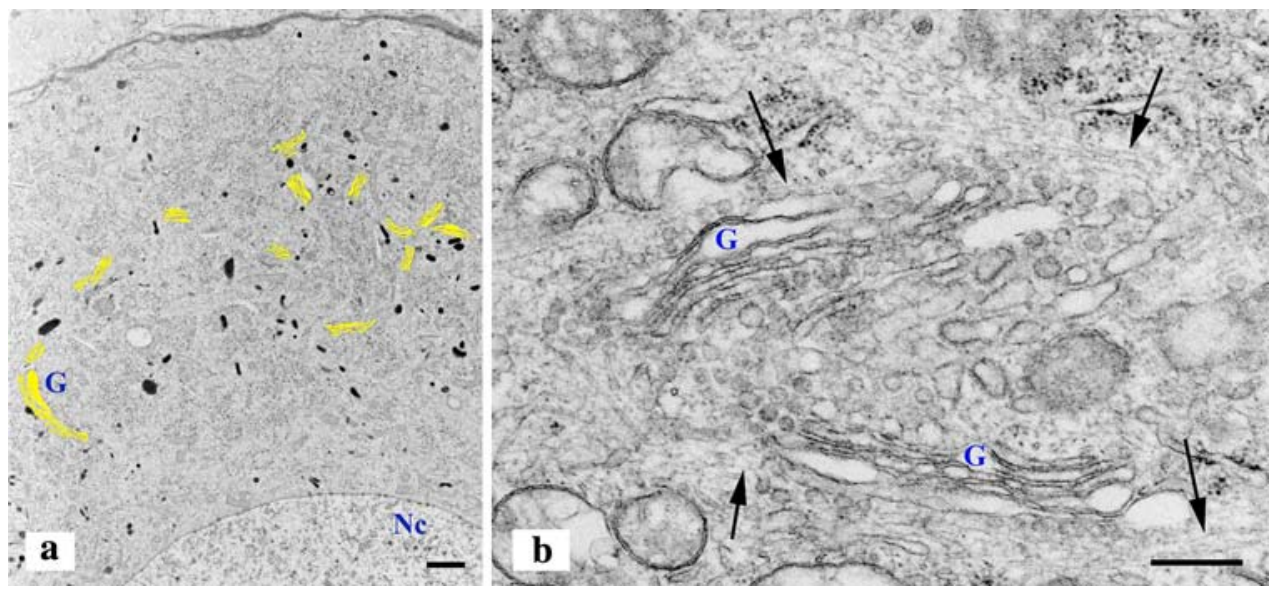


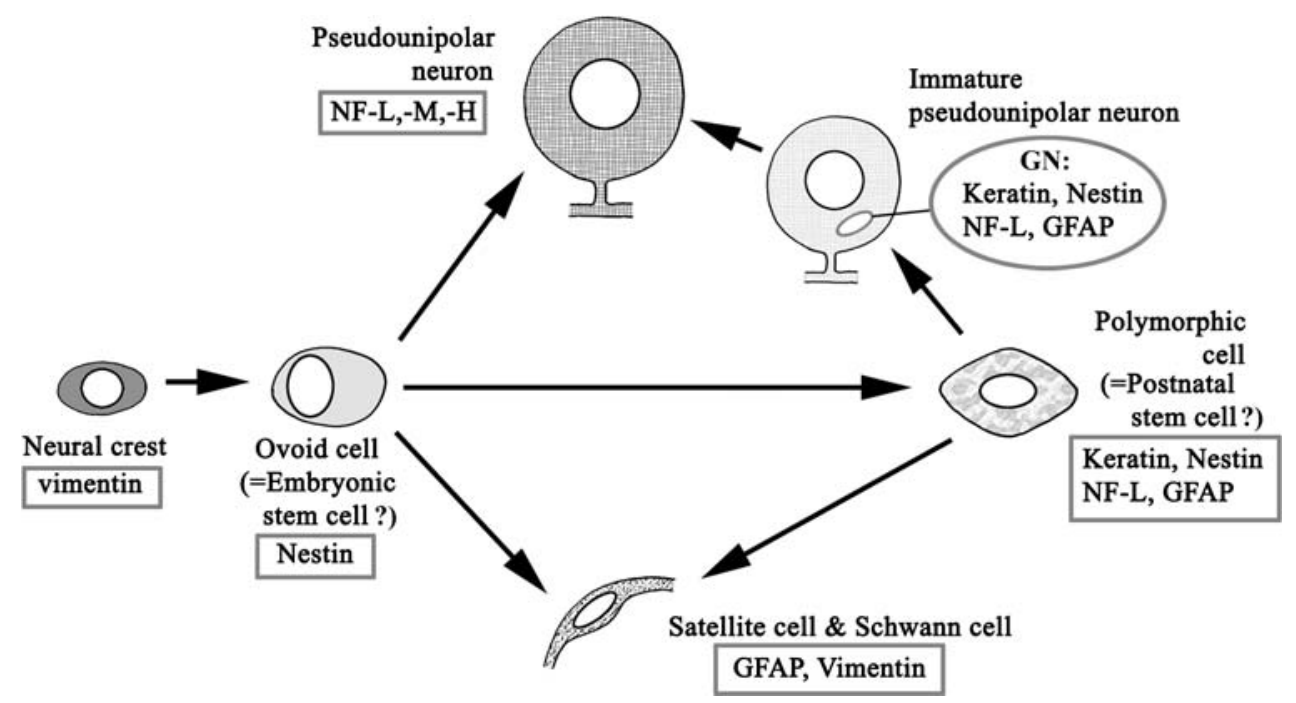

Fig. 6 Schematic representation of the embryonic and postnatal neurogeneses in the developing and adult rabbit spinal ganglia. Ovoid cells, which originate from the vimentin-positive neural crest, differentiate into NF-positive pseudounipolar neurons, GFAP/vimentin-positive glial cells (satellite cells and Schwann cells) and keratinpositive polymorphic cells during prenatal lives. Polymorphic cells,

ganglion cells. One was in embryonic neurogenesis and the other was in postnatal neurogenesis. The ganglion cells appeared to originate from the nestin-positive ovoid cells in the former and from the keratin-positive polymorphic cells in the latter. The keratin-positive neurons in the adult spinal ganglion seem to be immature neurons immediately after differentiation from these polymorphic cells.

\section{Embryonic neurogenesis}

Spinal ganglia arise from the neural crest (Pannese 1974). As shown in our results, the spinal ganglion at 15 days of gestation consisted of three kinds of cells, namely small cells expressing vimentin alone, spindle-shaped cells coexpressing vimentin and nestin, and nestin-positive ovoid cells with an eccentric nucleus. Migrating neural crest cells exclusively express vimentin (Boisseau and Simonneau 1989), and vimentin in their cytoplasm is progressively replaced by nestin after they migrate to the spinal ganglion (Kumano et al. 2002). Therefore, it seems that the vimentin-positive small cells are actually the neural crest cells immediately after migration to the ganglion and that the neural crest cells differentiate into nestin-positive ovoid cells with an eccentric nucleus through the spindle-shaped cells. Nestin has been utilized as a histochemical marker for identifying neural stem cells of the central nervous system (Zhao et al. 2003; Scheffler et al. 2005; Xu et al. 2005; Charrier et al. 2006). In the embryonic spinal ganglion, some ovoid cells co-expressed nestin with either NFL or GFAP. In addition, ovoid cells expressing nestin which express keratin 8, keratin 14, nestin, NF-L and GFAP, differentiate into pseudounipolar neurons and glial cells after birth. When the polymorphic cells differentiate into neurons, the immature neurons transiently express these five kinds of proteins as a Golgiassociated filament network $(G N)$

exclusively without keratin, NF-L and GFAP could not be observed in the postnatal spinal ganglion. Therefore, it may be considered that the nestin-positive ovoid cell with an eccentric nucleus is an embryonic neural stem cell of the spinal ganglion.

\section{Postnatal neurogenesis}

The possibility that postnatal ganglion cells arise from the keratin-positive polymorphic cells observed in the developing and adult spinal ganglia could be considered for the following three reasons. First, in the embryonic ganglion cells, co-expressions of vimentin and nestin and of nestin and keratin could be observed, but co-expression of vimentin and keratin could not be detected. Therefore, keratin-positive cells do not seem to be derived directly from the neural crest, but from nestin-positive ovoid cells with an eccentric nucleus, which may be considered to be embryonic neural stem cells as described above. Second, keratin-positive neurons could not be detected in either the embryonic or newborn spinal ganglia. Therefore, the keratin-positive polymorphic cells should not differentiate into neurons at the embryonic stage. Third, the keratin-positive polymorphic cells observed in developing and adult spinal ganglion co-expressed nestin, NF-L and GFAP. As is well known, undifferentiated neural epithelial cells express keratin (Maddox-Hyttel et al. 2003) and nestin (Lendahl et al. 1990). Keratin is detected not only in undifferentiated neural cells, but also in many kinds of redifferentiating tumor cells of the nervous system, as mentioned previously 
in "Introduction." Neurofilaments are co-assembled from NF-L and NF-M subunits during embryonic neurogenesis (Shaw and Weber 1982). In addition, satellite cells (Kobayashi et al. 1986; Stephenson and Byers 1995) and Schwann cells (Eng and Smith 1985; Jessen et al. 1990; Feinstein et al. 1992) express GFAP. Therefore, the keratin-positive polymorphic cell may be considered to be a postnatal neural stem cell of the spinal ganglion. Further studies using cell-culture model may help to verify our assumptions concerning the embryonic and postnatal stem cells of the spinal ganglion.

Golgi-associated network in the immature neuron

As shown in our results, in addition to the polymorphic cells, which may be considered to be postnatal neural stem cells as described above, a few pseudounipolar neurons also coexpressed five kinds of intermediate filament proteins, namely keratin 8 , keratin 14 , nestin, NF-L and GFAP, as peculiar granular or network structures. These structures were confirmed by immunoelectron microscopical and ultrastructural studies to be Golgi-associated filament networks surrounding the Golgi apparatus. Therefore, it seems that these five kinds of intermediate filament proteins, which locate diffusely around cytoplasm in the polymorphic cells, temporarily form a Golgi-associated filament network when the polymorphic cells differentiate into neurons. The components of this network may change into other intermediate filament proteins such as NF-M and NF-H with maturity of the neurons. Keratin filaments (Chou et al. 1994; Zhang et al. 1998) and neurofilaments (Hirokawa and Takeda 1998; Toivola et al. 2005) interact with the intracellular membrane system. Some intermediate filament-associated proteins that mediate interaction among some kinds of intermediate filaments have also been reported (Herrmann and Aebi 2000). Therefore, the Golgi-associated filament network, which consists of these five kinds of intermediate filament proteins, seems to be involved in maintaining the complex structure of the Golgi apparatus. The Golgi-associated filament network has already been recognized in the duct epithelial cells of the rabbit submandibular gland (Ogawa et al. 2002) and in the absorptive cells of the rabbit duodenum (Iwatsuki and Suda 2005a).

Keratin filaments consist of a specific combination of type I keratin and type II keratin (Albers and Fuchs 1992). The localization of keratin 8 and keratin 14 did not completely correspond in the keratin-positive polymorphic cells. Tight co-localization of both keratins was confirmed as a Golgi-associated network in a few immature neurons in the adult ganglion. Therefore, keratin 8 and keratin 14 form keratin filaments together only after the polymorphic cells differentiate into neurons, and the keratin filaments enter the Golgi-associated filament network.
Acknowledgments The authors express their sincere thanks to Prof. K. Sasaki for his many helpful suggestions throughout this work. They also acknowledge the skillful and substantial technical assistance of Mr. K. Uehira, Mr. T. Suda and Miss C. Itano. This study was partly supported by a Research Project Grant (no. 17-106N) from Kawasaki Medical School.

\section{References}

Albers K, Fuchs E (1992) The molecular biology of intermediate filament proteins. Int Rev Cytol 134:243-279

Anniko M, Arnold W, Thornell L-E, Virtanen I, Ramaekers FCS, Pfalts CR (1990) Regional variations in the expression of cytokeratin proteins in the adult human cochlea. Eur Arch Otorhinolaryngol 247:182-188

Azumi N, Battifora H (1987) The distribution of vimentin and keratin in epithelial and nonepithelial neoplasms. A comprehensive immunohistochemical study on formalin- and alcohol-fixed tumors. Am J Clin Pathol 88:286-296

Bignami A, Dahl D (1985) Glial filaments in brain differentiation and the transient expression of neurofilaments in Purkinje cell development. Ann N Y Acad Sci 455:563-574

Bignami A, Raju T, Dahl D (1982) Localization of vimentin, the nonspecific intermediate filament protein, in embryonal glia and in early differentiating neurons. In vivo and in vitro immunofluorescence study of the rat embryo with vimentin and neurofilament antisera. Dev Biol 91:286-295

Boisseau S, Simonneau M (1989) Mammalian neuronal differentiation: early expression of a neuronal phenotype from mouse neural crest cells in a chemically defined culture medium. Development 106:665-674

Bondurand N, Natarajan D, Thapar N, Atkins C, Pachnis V (2003) Neuron and glia generating progenitors of the mammalian enteric nervous system isolated from foetal and postnatal gut cultures. Development 130:6387-6400

Caselitz J, Walther B, Wustrow J, Seifert G, Weber K, Osborn M (1986) A monoclonal antibody that detects myoepithelial cells in exocrine glands, basal cells in other epithelia and basal and suprabasal cells in certain hyperplastic tissues. Virchows Arch A Pathol Anat Histopathol 409:725-738

Charrier C, Coronas V, Fombonne J et al (2006) Characterization of neural stem cells in the dorsal vagal complex of adult rat by in vivo proliferation labeling and in vitro neurosphere assay. Neuroscience 138:5-16

Chetty R, Pillay P, Jaichand V (1998) Cytokeratin expression in adrenal phaeochromocytomas and extra-adrenal paragangliomas. J Clin Pathol 51:477-478

Chou CF, Riopel CL, Omary MB (1994) Identification of a keratinassociated protein that localizes to a membrane compartment. Biochem J 298:457-463

Eng LF, Smith ME (1985) Recent studies of the glial fibrillary acidic protein. Ann N Y Acad Sci 455:525-537

Feinstein DL, Weinmaster GA, Milner RJ (1992) Isolation of cDNA clones encoding rat glial fibrillary acidic protein: expression in astrocytes and in Schwann cells. J Neurosci Res 32:1-14

Franke FE, Schachenmayr W, Osborn M, Altmannsberger M (1991) Unexpected immunoreactivities of intermediate filament antibodies in human brain and brain tumors. Am J Pathol 139:67-79

Guarino M (1993) Plexiform schwannoma. Immunohistochemistry of Schwann cell markers, intermediate filaments and extracellular matrix components. Pathol Res Pract 189:913-920

Herrmann H, Aebi U (2000) Intermediate filaments and their associates: multi-talented structural elements specifying cytoarchitecture and cytodynamics. Curr Opin Cell Biol 12:79-90 
Herrmann H, Hesse M, Reichenzeller M, Aebi U, Magin TM (2003) Functional complexity of intermediate filament cytoskeletons: from structure to assembly to gene ablation. Int Rev Cytol 223:83-175

Herrmann H, Bär H, Kreplak L, Strelkov SV, Aebi U (2007) Intermediate filaments: from cell architecture to nanomechanics. Nat Rev Mol Cell Biol 8:562-573

Hirokawa N, Takeda S (1998) Gene targeting studies begin to reveal the function of neurofilament proteins. J Cell Biol 143:1-4

Hsu YC, Lee DC, Chiu IM (2007) Neural stem cells, neural progenitors, and neurotrophic factors. Cell Transpl 16:133-150

Iwatsuki $H$ (1999) Vimentin intermediate filaments: function and implication in cell differentiation. Kawasaki Med J 25:39-58

Iwatsuki H, Suda M (2005a) Maturation of three kinds of keratin networks in the absorptive cells of rabbit duodenum. Acta Histochem Cytochem 38:237-245

Iwatsuki H, Suda M (2005b) Golgi-associated networks composed of keratin filaments, neurofilaments and actin filaments in pseudounipolar neurons. Acta Histochem Cytochem 38:S25

Iwatsuki H, Suda M (2007) Keratin 20 expressed in the endocrine and exocrine cells of the rabbit duodenum. Acta Histochem Cytochem 40:123-130

Iwatsuki H, Sasaki K, Suda M, Itano C (1999) Vimentin intermediate filament protein as differentiation marker of optic vesicle epithelium in the chick embryo. Acta Histochem 101:369-382

Iwatsuki H, Ogawa C, Suda M (2002) Vimentin-positive cells in the villus epithelium of the rabbit small intestine. Histochem Cell Biol 117:363-370

Jessen KR, Morgan L, Stewart HJS, Mirsky R (1990) Three markers of adult non-myelin-forming Schwann cells, 217c(Ran-1), A5E3 and GFAP: development and regulation by neuron-Schwann cell interactions. Development 109:91-103

Kashima T, Tiu SN, Merrill JE, Vinters HV, Dawson G, Campagnoni AT (1993) Expression of oligodendrocyte-associated genes in cell lines derived from human gliomas and neuroblastomas. Cancer Res 53:170-175

Kasper M (1992) Cytokeratins in intracranial and intraspinal tissues. Adv Anat Embryol Cell Biol 126:1-82

Katagata Y, Aoki T, Kawa Y, Mizoguchi M, Kondo S (1999) Keratin subunit expression in human cultured melanocytes and mouse neural crest cells without formation of filamentous structures. J Investig Dermatol Symp Proc 4:110-115

Kobayashi S, Chiu FC, Katayama M, Sacchi RS, Suzuki K, Suzuki K (1986) Expression of glial fibrillary acidic protein in the CNS and PNS of murine globoid cell leukodystrophy, the twitcher. Am J Pathol 125:227-243

Kumano I, Iwatsuki H, Sasaki K, Ogawa C (2001) Alterations in neuroepithelial intermediate filaments during neurogenesis in the chick cervical spinal cord. Kaibogaku Zasshi 76:483-490

Kumano I, Iwatsuki H, Sasaki K (2002) Ganglion cell differentiation and intermediate filaments in the cervical dorsal root ganglion of the chick embryo. Kawasaki Med J 28:57-69

Lendahl U, Zimmerman LB, McKay RDG (1990) CNS stem cells express a new class of intermediate filament protein. Cell 60:585-595

Li HY, Say EH, Zhou XF (2007) Isolation and characterization of neural crest progenitors from adult dorsal root ganglia. Stem Cells 25:2053-2065

Maddox-Hyttel P, Alexopoulos NI, Vajta G et al (2003) Immunohistochemical and ultrastructural characterization of the initial post- hatching development of bovine embryos. Reproduction 125:607-623

Messam CA, Hou J, Major EO (2000) Coexpression of nestin in neural and glial cells in the developing human CNS defined by a human-specific anti-nestin antibody. Exp Neurol 161:585-596

Moran CA, Rush W, Mena H (1997) Primary spinal paragangliomas: a clinicopathological and immunohistochemical study of 30 cases. Histopathology 31:167-173

Ogawa C, Iwatsuki H, Suda M, Sasaki K (2002) Golgi-associated filament networks in duct epithelial cells of rabbit submandibular glands: immunohistochemical light and electron microscopic studies. Histochem Cell Biol 118:35-40

Okabe H, Okubo T, Adachi H, Ishikawa T, Ochi Y (1997) Immunohistochemical demonstration of cytokeratin in human embryonic neurons arising from placodes. Brain Dev 19:347-352

Oshima RG (2007) Intermediate filaments: a historical perspective. Exp Cell Res 313:1981-1994

Pannese E (1974) The histogenesis of the spinal ganglia. Adv Anat Embryol Cell Biol 47:7-97

Rask-Andersen H, Boström M, Gerdin B et al (2005) Regeneration of human auditory nerve. In vitro/in video demonstration of neural progenitor cells in adult human and guinea pig spiral ganglion. Hear Res 203:180-191

Scheffler B, Walton NM, Lin DD et al (2005) Phenotypic and functional characterization of adult brain neuropoiesis. Proc Natl Acad Sci USA 102:9353-9358

Shaw G, Weber K (1982) Differential expression of neurofilament triplet proteins in brain development. Nature 298:277-279

Stephenson JL, Byers MR (1995) GFAP immunoreactivity in trigeminal ganglion satellite cells after tooth injury in rats. Exp Neurol 131:11-22

Takeuchi H, Kubota T, Sato K, Llena JF, Hirano A (2002) Epithelial differentiation and proliferative potential in spinal ependymomas. J Neurooncol 58:13-19

Tennyson VM (1965) Electron microscopic study of the developing neuroblast of the dorsal root ganglion of the rabbit embryo. J Comp Neurol 124:267-317

Toivola DM, Tao GZ, Habtezion A, Liao J, Omary MB (2005) Cellular integrity plus: organelle-related and protein-targeting functions of intermediate filaments. Trends Cell Biol 15:608617

Van Muijen GN, Ruiter DJ, Warnaar SO (1987) Coexpression of intermediate filament polypeptides in human fetal and adult tissues. Lab Invest 57:359-369

Walder S, Zhang F, Ferretti P (2003) Up-regulation of neural stem cell markers suggests the occurrence of dedifferentiation in regenerating spinal cord. Dev Genes Evol 213:625-630

$\mathrm{Xu} \mathrm{Y}$, Tamamaki N, Noda $\mathrm{T}$ et al (2005) Neurogenesis in the ependymal layer of the adult rat 3rd ventricle. Exp Neurol 192:251-264

Yamada M, Nakagawa M, Yamamoto M, Furuoka H, Matsui T, Taniyama H (1998) Histopathological and immunohistochemical studies of intracranial nervous-system tumours in four cattle. J Comp Pathol 119:75-82

Zhang B, Chen Y, Han Z, Ris H, Zhai Z (1998) The role of keratin filaments during nuclear envelope reassembly in Xenopus egg extracts. FEBS Lett 428:52-56

Zhao M, Momma S, Delfani K et al (2003) Evidence for neurogenesis in the adult mammalian substantia nigra. Proc Natl Acad Sci USA 100:7925-7930 